\title{
Transição paradigmática e meio ambiente: posição de dois grupos etários
}

Paradigmatic transition and environment: position of two age groups

\section{Transición paradigmática y medio ambiente: posición de dos grupos de edad}

\author{
Ariane Kuhnen $^{\mathrm{a}} \mathbb{D}^{\mathbb{D}}$; Maíra Longhinotti Felippe ${ }^{\mathrm{b}} \mathbb{D}$; Daniela Xavier Morais \\ a Doutora em Ciências Humanas, Departamento de Psicologia da Universidade Federal de Santa Catarina, Florianópolis, SC, Brasil - \\ E-mail: ariane.kuhnen@ufsc.br \\ b Doutora em Tecnologia da Arquitetura, Departamento de Arquitetura e Urbanismo da Universidade Federal de Santa Catarina, \\ Florianópolis, SC, Brasil. - E-mail: mairafelippe@gmail.com \\ c Mestre em Psicologia, Departamento de Psicologia da Universidade Federal de Santa Catarina, Florianópolis, SC, Brasil - Email: \\ daniela_xm@hotmail.com
}

\begin{abstract}
Resumo: O modo como as pessoas percebem, representam e valorizam o meio ambiente permite compreender comportamentos que o afetam. Assim, buscamos caracterizar as representações sociais da natureza, do meio ambiente e da água, e as crenças ambientais de 133 jovens e 100 adultos maduros. Os dados dos dois grupos etários foram comparados a fim de se poder vislumbrar a evolução do pensamento ecológico entre gerações. Utilizando a Escala NEP, encontramos um sistema de crenças biocêntrico para ambos os grupos etários, não tendo sido observada diferença estatisticamente significativa entre eles. As representações sociais, obtidas através de questionário de evocações livres, também se apresentaram similares nos dois grupos. Verificamos, todavia, que a identificação ao paradigma biocêntrico não foi confirmada pelo estudo das representações sociais, que apontou tanto elementos biocêntricos como antropocêntricos. Tais contradições sugerem um processo gradual de transição de paradigmas, em que ambas as visões de mundo coexistem.
\end{abstract}

Palavras-chave: Psicologia ambiental. Representação social. Atitudes. Meio ambiente.

Abstract: The way in which people perceive, represent and value the environment allows understanding behaviors that affect it. Thus, we sought to characterize the social representations of nature, environment and water, and the environmental beliefs of 133 young people and 100 mature adults. Two age groups' data were compared in order to glimpse the evolution of ecological thinking between generations. By using the NEP Scale, we found a biocentric belief system for both age groups, with no statistically significant difference between them. The social representations, obtained through a questionnaire of free evocations, were also similar in both groups. However, we verified that the identification to the biocentric paradigm was not confirmed by the study of social representations, which showed both biocentric and anthropocentric elements. These contradictions suggest a gradual transition of paradigm, in which both worldviews coexist.

Keywords: Environmental psychology. Social representation. Attitudes. Environment.

Resumen: El modo en que las personas perciben, representan y valoran el medio ambiente permite comprender comportamientos que lo afectan. Así, buscamos caracterizar las representaciones sociales de la naturaleza, del medio obra, forneça um link para a licença, e indicar se foram feitas alterações. 
ambiente y del agua, y las creencias ambientales de 133 jóvenes y 100 adultos maduros. Los datos de los dos grupos de edad se compararon para poder vislumbrar la evolución del pensamiento ecológico entre generaciones. Utilizando la Escala NEP, encontramos un sistema de creencias biocéntricas para ambos grupos de edad, no habiéndose observado diferencia estadísticamente significativa entre ellos. Las representaciones sociales, obtenidas a través de un cuestionario de evocaciones libres, también se presentaron similares en los dos grupos. Sin embargo, comprobamos que la identificación al paradigma biocéntrico no fue confirmada por el estudio de las representaciones sociales, que apuntó tanto elementos biocéntricos como antropocéntricos. Tales contradicciones sugieren un proceso gradual de transición de paradigmas, en que ambas visiones de mundo coexisten.

Palabras clave: Psicología ambiental. Representación social. Actitudes. Medio ambiente.

\section{Como citar o artigo:}

KUHNEN, A. FELIPPE, M. L. MORAIS, D. X. Transição paradigmática e meio ambiente: posição de dois grupos etários. Revista de Ciências Humanas, Florianópolis, v. 53, 2019 DOI: 10.5007/2178-4582.2019.e59697.

\section{INTRODUÇAO}

Os problemas ambientais originam-se da sensível relação que o ser humano vem estabelecendo com o meio circundante, a qual privilegia a satisfação imediata de prazeres e necessidades humanas individuais ou grupais. Desse modo, preocupar-se com o planeta requer, acima de tudo, concentrarse no comportamento humano, reconhecendo os problemas ambientais como problemas humanoambientais (PINHEIRO, 2002). Faz-se necessário alcançar determinados aspectos intervenientes na relação pessoa-ambiente (RAYMUNDO; KUHNEN, 2010). Aspectos psicológicos permeiam tal interação, isto é, o modo como o ser humano age sobre o ambiente e, ao mesmo tempo, como esse ambiente influencia o próprio comportamento humano (KUHNEN, 2009). A Psicologia Ambiental surgiu como área de estudos que se dedica especificamente a estudar essa interveniência ao investigar a relação entre pessoas e ambientes a partir de uma visão bidirecional, ou seja, que considera a influência recíproca estabelecida entre os elementos envolvidos (KUHNEN, 2004; WIESENFELD, 2005). Tal inter-relação compreende dois aspectos: a forma como a pessoa valoriza, percebe, representa e sente o ambiente que a circunda e o comportamento que se dá a partir disso, o que ocorre em um fluxo contínuo, mutuamente consequente.

Segundo Corral-Verdugo, Varela-Romero e González-Lomelí (2004), as crenças e os valores ambientais elaborados por indivíduos e grupos são um preditivo do comportamento de preservar o meio físico. Elas surgem como demandas pessoais e sociais necessárias à formação de competência pró-ambiental, ou "capacidade de responder efetivamente a exigências de conservação ambiental" (CORRAL-VERDUGO, 2002, p. 535). O planeta vem sofrendo uma série de mudanças significativas, muitas delas derivadas da ação humana sobre a natureza. Isso leva a mudanças sociais e exige uma série de ajustamentos dos indivíduos à vida cotidiana, modificando seu entendimento sobre a relação pessoa-ambiente e, consequentemente, seu comportamento em direção à conservação de sistemas ambientais. Nesse sentido, a Psicologia Ambiental busca suporte em outros campos de estudo, 
internos ou externos à Ciência Psicológica (KUHNEN, 2010), para auxiliar na compreensão do pensamento social acerca da relação do ser humano com a natureza, a água e o meio-ambiente, utilizando a Teoria das Representações Sociais (MOSCOVICI, 1978).

As representações sociais compreendem o conhecimento elaborado e compartilhado por um determinado grupo, que constrói uma realidade comum a partir da significação de um determinado objeto ou fato social. Essa significação é um conjunto de conhecimentos e crenças que surgem principalmente da comunicação entre indivíduos e grupos e, direcionam a ação dos sujeitos no meio social, além de atribuir significado à realidade cotidiana vivenciada por estes. Assim sendo, pode-se conceber a representação social como algo estruturado socialmente, que influencia o pensamento e, consequentemente, a forma de se relacionar com o mundo. A investigação das representações sociais leva, desse modo, ao entendimento do senso comum, isto é, o conhecimento produzido pelas pessoas em seu dia-a-dia, e permite ainda compreender a forma como o conhecimento científico é apropriado pelos grupos sociais (JODELET, 2001; MOSCOVICI, 1978).

Complementar à Teoria das Representações Sociais, a Teoria do Núcleo Central (ABRIC, 1994) possibilita o aprofundamento dos conhecimentos oriundos das representações sociais. Ela indica a existência de um núcleo central que permite a identificação dos principais elementos da representação, segundo a posição que ocupam na elaboração dos significados, podendo ser central ou periférica (ABRIC, 1994; 1998). Abric (1994) compreende o núcleo central como uma estrutura consensual, estável e relacionada ao contexto social global, enquanto o sistema periférico representa a adequação do indivíduo aos valores do núcleo central, baseada no contexto imediato por ele vivenciado cotidianamente. Por isso, o sistema periférico suporta diferenças individuais e é mais flexível às transformações que se dão pelas novas interpretações individuais sobre o objeto ou fato. A análise estrutural prioriza o processo de objetificação das representações (transformação do novo objeto, que é abstrato, em algo concreto por meio de imagens ou ideias) (MOSCOVICI, 1981; VALA, 2006; WACHELKE; CAMARGO, 2007) e possibilita a compreensão de seu funcionamento e influência sobre os comportamentos (ABRIC, 1994; GUIMELLI, 1993), motivo pelo qual foi utilizada neste estudo.

Além das contribuições da Teoria das Representações Sociais, foi realizada a identificação de sistemas de crenças sobre o ambiente, por meio da perspectiva Sociológica do Novo Paradigma Ecológico - NEP, proposto em 1978 por Dunlap e Van Liere. Essa perspectiva propõe a existência de dois sistemas de crenças sobre as relações do ser humano com o ambiente: o antropocêntrico ou paradigma social dominante - vigente há anos nas sociedades ocidentais e relacionado ao controle e a utilização da natureza em benefício do ser humano, que se considera independente e superior a outros organismos da natureza - e o biocêntrico ou novo paradigma ambiental, pensamento emergente no qual o direito à vida sob qualquer forma é fundamental e os seres humanos são 
identificados como parte do ambiente natural, valorizado per se (DUNLAP et al., 2000; NASCIMENTO-SCHULZE et al., 2002). De acordo com Riley Dunlap et al. (2000) e Clélia Nascimento-Schulze et al. (2002), essas crenças - que constituem um paradigma ou visão de mundo — influenciam atitudes e outras crenças direcionadas às questões ambientais. Podem ainda indicar mudanças comportamentais, pois criam barreiras e/ou oportunidades em direção a comportamentos de preservação do meio físico.

Destacáveis estudos servem de referência à preocupação, inerente à Psicologia Ambiental, de entender a interveniência entre aspectos humanos e ambientais (PINHEIRO, 2003; STOKOLS, 1978; VALERA, 1996). Muitos autores (CASTRO, 2005; AMÉRIGO, 2009; HAWCROFT; MILFONT, 2010) têm encontrado resultados que indicam grande adesão ao novo paradigma ecológico, relacionados a atribuição de valores intrínsecos à natureza, senso de preservação e atitudes abrangentes em relação às questões ambientais, o que indica crenças pró-ambientais compatíveis com o Novo Paradigma Ecológico (NEP). Contudo, para Castro (2003), a mudança do paradigma dominante para o novo paradigma não ocorre de forma abrupta, pois faz parte de um processo que admite sua coexistência. Portanto, há a necessidade de aprofundar os conhecimentos sobre as atitudes pró-ambientais, levando a uma construção do meio ambiente como objeto social (AMÉRIGO, 2009).

Conhecer o modo como as pessoas percebem, representam e valorizam o ambiente permite tanto compreender comportamentos que o afetam como produzir estratégias de intervenção que visam à promoção de condutas pró-ambientais, tema recorrente dentre aqueles aos quais os estudiosos da Psicologia Ambiental se dedicam (BERTOLDO; CASTRO; BOUSFIELD, 2013; CORRALIZA; BETHELMY, 2011; CORRALIZA; COLLADO; BETHELMY, 2013; OLIVOS; ARAGONÉS, 2013; POLLI; KUHNEN, 2011; SEVILLANO; ARAGONÉS, 2009). As duas perspectivas (representações sociais e NEP) são importantes contribuições nessa investigação. Esse estudo objetiva caracterizar as representações sociais de natureza, meio ambiente e água - elementos do senso comum na temática ambiental - e o sistema de crenças ecológicas, se antropocêntrico ou biocêntrico. Considera-se também que o pensamento social constitui-se da posição que se encontram os sujeitos na sociedade e que, diferentes grupos etários - em função de seus distintos papéis sociais e de vivenciarem momentos distintos no ciclo de vida - podem vir a perceber o ambiente diferentemente. Portanto comparou-se o grupo de jovens e de adultos maduros a fim de vislumbrar a evolução do pensamento ecológico entre gerações e possíveis desdobramentos (direções) para o futuro. 


\section{MÉTODO}

Esse estudo possui uma estratégia de pesquisa qualitativo-quantitativa. Trata-se de um levantamento de dados do tipo descritivo-correlacional. A coleta dos dados ocorreu no Campus Universitário David Ferreira Lima, da Universidade Federal de Santa Catarina, em Florianópolis (SC). A população que o frequenta compreende servidores da instituição (docentes e técnicos administrativos), estudantes e pessoas da comunidade que utilizam os serviços prestados à comunidade.

\section{PARTICIPANTES}

Os dois grupos etários compreendem um grupo de jovens, constituído por 133 estudantes universitários, sendo 66 do sexo feminino e 67 do sexo masculino, com média de idade de 21 anos e 3 meses, idade mínima de 17 anos e máxima de 37 anos; e um grupo de adultos maduros, formado por 100 indivíduos, sendo 64 do sexo feminino e 36 do sexo masculino, com média de idade de 62 anos e 8 meses, idade mínima de 50 anos e máxima de 87 anos. No grupo de adultos maduros, estiveram presentes 26 docentes, 1 discente, 5 integrantes da Associação dos Aposentados e Pensionistas da Universidade Federal de Santa Catarina e 68 participantes do Núcleo de Estudos da Terceira Idade (NETI). Utilizou-se uma amostra não-probabilística intencional da população, em que os participantes foram abordados com base no critério etário. A participação dos sujeitos foi anônima e voluntária.

\section{INSTRUMENTOS}

Utilizaram-se dois instrumentos, a Escala NEP (New Ecological Paradigm ou Novo Paradigma Ecológico), revisada conforme Dunlap et al. (2000), e um questionário de evocações livres. A Escala NEP revisada foi preenchida pelos respondentes e continha 15 itens, dentre os quais 8 representavam posicionamentos favoráveis ao novo paradigma ambiental (sistema biocêntrico) e 7 , desfavoráveis (sistema antropocêntrico). É constituída por cinco dimensões (três itens por dimensão): os limites reais de crescimento, o anti-antropocentrismo, a fragilidade do equilíbrio da natureza, a rejeição da exclusão do ser humano da natureza e a possibilidade de uma crise ambiental. Para cada item, houve cinco opções de resposta: concordo totalmente, concordo parcialmente, não concordo nem discordo, discordo parcialmente e discordo totalmente, segundo o grau de concordância do participante em relação às afirmações. $\mathrm{O}$ valor 5 foi atribuído às respostas que corresponderam à concordância total com o novo paradigma ambiental, e o valor 1 , à concordância total com o 
paradigma social dominante. Dessa forma, quanto maior o escore resultante, mais biocêntrica foi a visão de mundo manifestada pelo respondente.

Por meio do questionário de evocações livres, foram identificadas as representações sociais da natureza, do meio ambiente e da água, e sua base estrutural. O questionário, respondido sob a forma de entrevista, foi organizado em duas partes. A primeira continha questões sobre o sexo e a idade do participante, seu tempo de vinculação à universidade, o setor da instituição ao qual está vinculado, a cidade e o estado de sua procedência. A segunda parte do instrumento compreendia três questões. Em cada uma delas, solicitou-se aos participantes que indicassem cinco palavras ou expressões que lhe vinham imediatamente à mente ao se falar em natureza, meio ambiente e água, respectivamente. Solicitou-se igualmente que assinalassem duas palavras ou expressões, dentre as cinco evocadas, consideradas mais importantes. A escolha dos termos natureza e meio ambiente deveu-se à possibilidade de convergências e divergências de significado entre os termos. Água, por sua vez, é um dos termos mais recorrentes na mídia mundial e nos programas educacionais formais e informais, vinculados à preservação dos recursos naturais, ocupando, possivelmente, importante posição dentre os significados atribuídos à preservação ambiental.

\section{PROCEDIMENTOS}

Os dados foram coletados em dois momentos distintos. Inicialmente junto aos jovens, ao longo do segundo semestre de 2009 e o primeiro de 2010. Em momento posterior, durante o segundo semestre de 2010 e o primeiro de 2011, investigou-se o grupo de adultos maduros. Devido à facilidade de acesso, os jovens foram abordados espontaneamente enquanto frequentavam as instalações da universidade. Já docentes e discentes do grupo adultos maduros foram contatados previamente via telefone ou e-mail. Definido o interesse de participação foram agendados data, horário e local para a aplicação dos instrumentos. Realizou-se igualmente contato com as coordenações do Núcleo de Estudos da Terceira Idade e com a Associação dos Aposentados e Pensionistas da Universidade Federal de Santa Catarina, solicitando autorização de contato com os seus frequentadores nas instalações dos referidos locais. Todos os participantes responderam em uma mesma ocasião os dois instrumentos previstos, e assinaram um termo de consentimento de participação contendo esclarecimentos sobre o estudo ${ }^{1}$.

\footnotetext{
${ }^{1} \mathrm{O}$ termo de consentimento e o projeto de pesquisa das duas fases do estudo foram submetidos ao Comitê de Ética em Pesquisas com Seres Humanos da Universidade Federal de Santa Catarina e aprovados sob os números de protocolo 360 de 05/10/2009 e 992 de 10/09/2010.
} 


\section{ANÁLISE DE DADOS}

Os dados fornecidos pela Escala NEP e a primeira parte do questionário de evocações livres foram analisados conjuntamente para ambos os grupos etários com o auxílio do SPSS (Statistical Package for the Social Sciences). Realizou-se a análise estatística descritiva e relacional dos dados, buscando possíveis diferenças entre os grupos jovens e adultos maduros quanto às crenças ambientais. As palavras e expressões recolhidas na segunda parte do questionário de evocações livres foram analisadas de forma lexicográfica, separadamente para os dois grupos etários, com o auxílio do programa Evocation 2000. Tal análise informou frequências e ordem de citação das evocações. A centralidade das representações sociais de natureza, meio ambiente e água foi obtida através da indicação pelos respondentes das palavras ou expressões que consideravam mais importantes: uma palavra ou expressão indicada como mais importante acima de 50\% das vezes em que havia sido citada foi avaliada como pertencente ao núcleo central da representação social, e os demais casos, como pertencentes ao sistema periférico. Não foram consideradas nesta análise, seja para a definição do núcleo central, seja para a definição da estrutura periférica da representação social, as palavras com o menor número de citações cuja ordem média de evocação fosse igual ou superior à terceira posição, dentre as cinco possíveis ${ }^{2}$.

\section{RESULTADOS E DISCUSSÃO}

Os dados fornecidos pela Escala NEP foram agrupados em um único conjunto de dados, alocando-se os participantes na modalidade jovens ou adultos maduros, segundo o grupo etário ao qual pertenciam. As análises de consistência interna e fatorial executadas sugeriram a retirada de quatro itens da escala (itens de número 4, 6, 9 e 14), obtendo-se um $\alpha$ de Cronbach igual a 0,60. Verificou-se, então, que a mediana ${ }^{3}$ dos escores obtidos pelos 233 participantes, em resposta à Escala NEP, foi igual a 4,00 $(A=2,73)$, sendo o valor mínimo de 2,27 e o valor máximo de 5,00 . Os indivíduos do grupo jovens, que corresponderam a 57,10\% da amostra, forneceram escores apenas ligeiramente mais altos $(M d n=4,00 ; A=2,45)$ que os participantes do grupo adultos maduros (Mdn $=3,91 ; A=2,55), 42,90 \%$ da amostra. Os resultados evidenciaram uma atitude positiva por parte de ambos os grupos em relação à adesão ao Novo Paradigma Ecológico, indicando um sistema de crenças biocêntrico. A fim de verificar a existência de diferença estatisticamente significativa entre

\footnotetext{
${ }^{2}$ As palavras e expressões excluídas da análise estrutural corresponderam àquelas pertencentes ao quadrante inferior direito do quadro analítico final apresentado pelo programa Evocation.

${ }^{3}$ Utilizou-se a mediana $(M d n)$ como medida de tendência central, bem como a amplitude $(A)$ e os valores mínimos e máximos como medidas de dispersão, por serem indicados nos casos em que se observa assimetria na distribuição dos dados (DANCEY; REIDY, 2006).
} 
jovens e adultos maduros quanto à adesão ao Novo Paradigma Ecológico, utilizou-se o teste nãoparamétrico Mann-Whitney $(U)$ visto que a análise dos histogramas de frequência para as duas condições estudadas acusou assimetria na distribuição dos dados. Assim, obteve-se $U=6362(\mathrm{z}=$ $0,57)$ com um valor de probabilidade associada $(p)$ de 0,571 . Esse resultado indica não existir evidências de uma diferença estatisticamente significativa entre os grupos, o que corrobora os achados de Polli e Camargo (2016), que também não encontraram diferenças significativas entre participantes de diferentes grupos etários ao investigarem crenças e representações sociais de meio ambiente. No referido estudo, os participantes de todas as faixas etárias apresentaram crenças relacionadas ao novo paradigma ambiental.

Os dados obtidos também corroboram outras pesquisas realizadas (AMÉRIGO, 2009; HAWCROFT; MILFONT, 2010), nas quais os participantes se mostravam mais biocêntricos que antropocêntricos, e não houve a identificação de relação entre o sistema de crenças ecológicas e o gênero dos participantes, que por serem variáveis sociodemográficas podem ser equiparadas à variável grupo etário. Entende-se que a perspectiva do Novo Paradigma Ecológico propõe dois sistemas de crenças distintos e bem definidos: o biocêntrico e o antropocêntrico, e a partir da percepção da importância dos problemas ambientais, estaria havendo uma mudança de paradigma em direção ao biocêntrico. Essa mudança vem possivelmente ocorrendo, pois, de acordo com Paula Castro (2005), alguns resultados de pesquisas, com o uso da Escala NEP em diferentes contextos, têm indicado alto nível de adesão ao Novo Paradigma Ecológico. O posicionamento das pessoas tem sido mais claro, revelando uma maior preocupação com as questões ambientais, o que é confirmado por Ronald Inglehart e Paul Abramson (1999), ao concluírem que o aumento das preocupações com o meio ambiente se deve a uma maior sensibilização ambiental.

Esperava-se que os jovens apresentassem uma postura mais ativa e pró-ecológica diante das questões ambientais, devido à substituição gradual dos valores. Os mais velhos, apesar de compartilharem pensamentos voltados ao biocentrismo, tenderiam a apresentar-se mais distantes dessa posição. Essa diferença entre gerações, entretanto, não se confirmou nesta pesquisa. Uma interpretação possível para essa questão é o fato do meio ambiente ter se tornado um objeto social. Isso pode ser percebido através dos sistemas de ensino e dos meios de comunicação, que cada vez mais têm abordado temas relacionados ao meio ambiente, não apenas para divulgar problemas e “catástrofes" ambientais, mas atuando de forma a orientar e educar a todos acerca das consequências do comportamento humano para a humanidade e para a natureza.

María Amérigo (2009) ressaltou que a relação entre o antropocentrismo e o biocentrismo não é clara na atualidade, e este último, por se tratar de um paradigma emergente, não está ainda cristalizado na sociedade. Para a autora, existe a possibilidade de encontrarmos indivíduos antropocêntricos que oferecem manifestações sutis de ambientalismo, indicando a coexistência 
dessas duas dimensões. Ou ainda, pessoas que não apresentam claramente nenhuma dessas características. Assim, o meio ambiente pode ser percebido de acordo com a dimensão antropocêntrica (relativa ao "eu"), a partir de sua utilidade para o ser humano, e ainda ser adequado a uma visão biocêntrica (relativa ao "outro"), na qual se atribui valores intrínsecos à natureza (AMÉRIGO, 2009). Portanto, é indispensável reconhecer que as visões de mundo antropocêntrica e biocêntrica podem coexistir em um mesmo grupo. Ainda, segundo Amérigo (2009), há a necessidade de se aprofundar os conhecimentos sobre as atitudes pró-ambientais, levando-se a uma construção do meio ambiente como objeto social.

De acordo com Castro (2003), a mudança de um paradigma para outro não ocorre com a simples mudança de um pensamento. Isso se confirma através da investigação das representações sociais, que indicam a coexistência de novos e antigos pensamentos e a estreita relação que se estabelece entre eles. Concordando com essa autora, essa pesquisa buscou explicações para tais crenças através da investigação das representações sociais de elementos sociais presentes no senso comum. Entende-se que as representações sociais podem permitir uma compreensão mais ampla das crenças encontradas, já que admitem a existência de contradições.

Ao investigar as representações sociais do grupo jovens por meio do questionário de evocações livres, obtiveram-se 654 palavras ou expressões a partir do termo indutor natureza, sendo 153 evocações diferentes umas das outras. A análise realizada a partir da importância dada às palavras pelos respondentes indicou que floresta, meio-ambiente, preservação, água, ar-puro, equilíbrio, liberdade, sustentabilidade e vida representam possivelmente os elementos do núcleo central; enquanto os termos fauna, verde, árvores, animais, flores, mar, Amazônia, beleza, destruição, mato, plantas e rio compõem o sistema periférico da representação. De acordo com esses resultados, alcançou-se que os jovens representam a natureza como um equilibrio de elementos naturais (floresta, água, ar-puro, meio-ambiente), obtido também através da preservação e sustentabilidade, possibilitando vida e liberdade. Já entre os adultos maduros, foram constatadas 474 evocações, havendo 143 palavras ou expressões diferentes. A análise lexicográfica indicou as palavras água, florestas, vida, mares e Deus como elementos do núcleo central, e as palavras beleza,flores, árvores, animais, pássaros, rios, plantas, preservação e verde como pertencentes ao sistema periférico da representação social. Assim, é possível inferir que os adultos maduros compreendem a natureza como um conjunto de elementos naturais (água, florestas e mares), relacionados à vida e a Deus.

Para ambos os grupos etários, verificou-se a presença de elementos naturais, o que corrobora com o estudo de Castro (2005), que apontou a natureza como sendo representada, na maioria das vezes, "pelos objetos que a compõem - rios, florestas, animais" (p. 172). A palavra vida também compareceu no núcleo central da representação de ambos os grupos pesquisados, na mesma direção 
dos resultados da pesquisa conduzida por Amérigo (2009), em que a natureza foi identificada principalmente como fonte de vida.

Segundo Castro (2005), a palavra natureza é dotada de múltiplos sentidos. No entanto, uma de suas características mais marcantes é a de ser concebida como um termo que diferencia o que não é humano do que é humano. Dessa forma, faz oposição ao ser humano e representa uma construção social e histórica independente, possivelmente desde a antiguidade. Na presente investigação, tal oposição foi percebida diferentemente nas respostas dos participantes de ambas as faixas etárias. Entre os jovens, foram evocadas as palavras preservação e sustentabilidade, o que sugere que a ação humana é responsável pela natureza e exerce influência sobre ela. Ela também inspira liberdade, possivelmente devido aos momentos de prazer e lazer que proporciona ao ser humano. Este último parece preocupar-se com o equilíbrio dos elementos naturais, levando à gestão desses elementos, mas a fim de poder usufruí-los, o que é confirmado pela presença do elemento meio ambiente no núcleo central, termo que pode indicar uma interação humano-ambiental. Os sujeitos do grupo adultos maduros, entretanto, não atribuíram à natureza nenhuma característica indicativa da ação humana. Parecem compreendê-la como algo independente da intervenção humana, o que é confirmado pela presença da palavra Deus no núcleo central. Atribuíram ao poder divino a existência da natureza, independentemente do ser humano.

Com relação ao termo indutor meio ambiente, obtiveram-se para os sujeitos do grupo jovens 659 palavras evocadas e 186 palavras diferentes entre si. A análise realizada a partir da importância dada às palavras pelos respondentes indicou que ecossistema, interação, preservação, sustentabilidade, consciência, respeito e sociedade representam possivelmente os elementos do núcleo central; enquanto os termos animais, desmatamento, destruição, fauna, flora, natureza, poluição, ser humano, água, cuidado, equilíbrio, floresta, verde, vida, árvore, ecologia, efeito estufa e lixo compuseram o sistema periférico da representação. De acordo com esses resultados, compreende-se que os jovens representaram o meio-ambiente como um conjunto de interações ecossistêmicas e humanas, pautadas no respeito, na preservação e na sustentabilidade. Já os participantes com mais de 50 anos evocaram 474 palavras, sendo 164 diferentes entre si. A análise lexicográfica indicou as palavras cuidado, preservação, água, vida e seres humanos como elementos do núcleo central, e as palavras lixo, poluição, animais, florestas, limpeza, reciclagem e sustentável como pertencentes ao sistema periférico da representação social. Compreende-se, então, que os adultos maduros associaram o meio ambiente à vida, seres humanos, cuidado, preservação e água. Percebe-se nessa representação, um destaque para o elemento natural água e uma maior associação do termo indutor com a ação humana, que aparece fortemente em ambas as faixas etárias.

Esse resultado vai ao encontro do que indicou Castro (2003), para quem o ambiente é concebido pelas pessoas como aquilo que elas mesmas poluem e sujam e, portanto, cabe-lhes o papel 
de preservá-lo. Os termos sustentabilidade e interações ecossistêmicas, encontrados na atual pesquisa, relacionam-se igualmente a possíveis consequências que o ser humano pode vir a sofrer se não preservar e cuidar do meio ambiente. $\mathrm{O}$ termo respeito sugere ainda que a intervenção humana sobre o meio ambiente deve ser positiva. Nas evocações dos sujeitos mais velhos, as palavras água e vida ratificaram tal concepção de meio ambiente, pois representam elementos diretamente associados à sobrevivência, a qual parece depender do uso adequado dos recursos naturais.

Por fim, diante do termo indutor água, os sujeitos do grupo jovens evocaram 666 palavras, sendo 187 diferentes. A análise lexicográfica indicou como elementos do núcleo central da representação: escassez, essencial, rio, vida, desperdício, saúde, esgoto, indispensável, limpa e saneamento. Para esse grupo etário, o sistema periférico foi representado pelas seguintes palavras: mar, peixes, poluição, pura, sede, tratamento, chuva, natureza, necessidade, azul, potável, praia $\mathrm{e}$ sobrevivência. Portanto, pode-se inferir que esse grupo representa a água como um recurso indispensável à vida e a saúde, devendo ser limpa e tratada. Precisa ser preservada, evitando-se o desperdício que pode levar à escassez. Os participantes do grupo adultos maduros indicaram 485 palavras, sendo 140 diferentes umas das outras. A análise realizada a partir da importância dada às palavras pelos respondentes indicou que vida, sede, preservação e sobrevivência representam possivelmente os elementos do núcleo central; enquanto os termos limpeza, poluição, rios, saúde, mares, pura, cristalina, importante, necessidade, peixes e potável compuseram o sistema periférico da representação. Por conseguinte, os adultos maduros representam a água como um elemento necessário à vida, a sobrevivência e a saúde, devendo ser preservada, evitando-se sua poluição.

Obtiveram-se resultados fortemente relacionados à ação humana com o termo indutor água. Esse elemento natural foi compreendido de forma muito similar pelos participantes dos dois grupos etários. A água foi concebida como elemento indispensável ao ser humano, que deve ser preservada para se evitar a escassez e garantir a saúde e a sobrevivência (vida). Além disso, em ambas as representações sociais, compareceram termos relacionados à poluição e ao tratamento da água, sugerindo que não há uma valorização do recurso por si mesmo, e sim, um interesse nos benefícios que ele proporciona ao ser humano.

Os resultados das representações sociais de natureza, meio ambiente e água, entre jovens e adultos maduros mostraram pontos em comum (ver Figura 1). No entanto, diferenças foram percebidas quanto à concepção de natureza, que para os adultos maduros emergiu como algo de caráter divino e independente da intervenção humana, tendo os jovens considerado a ação das pessoas responsável pela natureza e influente sobre ela. Essa diferença poderia ser entendida a partir das atividades e experiências cotidianas comuns em cada um dos dois grupos em relação ao objeto representado, experiências estas que compõem um momento específico da vida e contribuem no processo de formação das representações sociais. Por exemplo, seria possível hipotetizar que os 
jovens possuem um contato mais frequente com o meio natural que o grupo de adultos maduros, usufruindo-o em suas atividades de lazer, fato que poderia levá-los a uma maior associação do termo natureza a elementos que evidenciam a presença ou a ação humana. Mas também é possível que os jovens estejam respondendo mais ao chamado 'discurso atual' sobre o meio ambiente, refletindo acerca da responsabilidade das pessoas com relação aos danos causados e à necessária preservação. Não há, como no caso dos adultos maduros, uma ênfase no efeito, em si, da destruição (como a poluição, por exemplo). Senão uma reflexão acerca de processo, causalidade e responsabilidade. Apesar dessa diferença, encontraram-se nos dois grupos etários, em linhas gerais, elementos de um discurso centrado no ser humano, sob uma perspectiva de controle e utilidade dos recursos naturais. Contudo, também se verificou a valorização de características intrínsecas à natureza, o que é característico de sujeitos biocêntricos (AMÉRIGO, 2009; HAWCROFT; MILFONT, 2010).

\section{crença ambiental: biocentrismo}

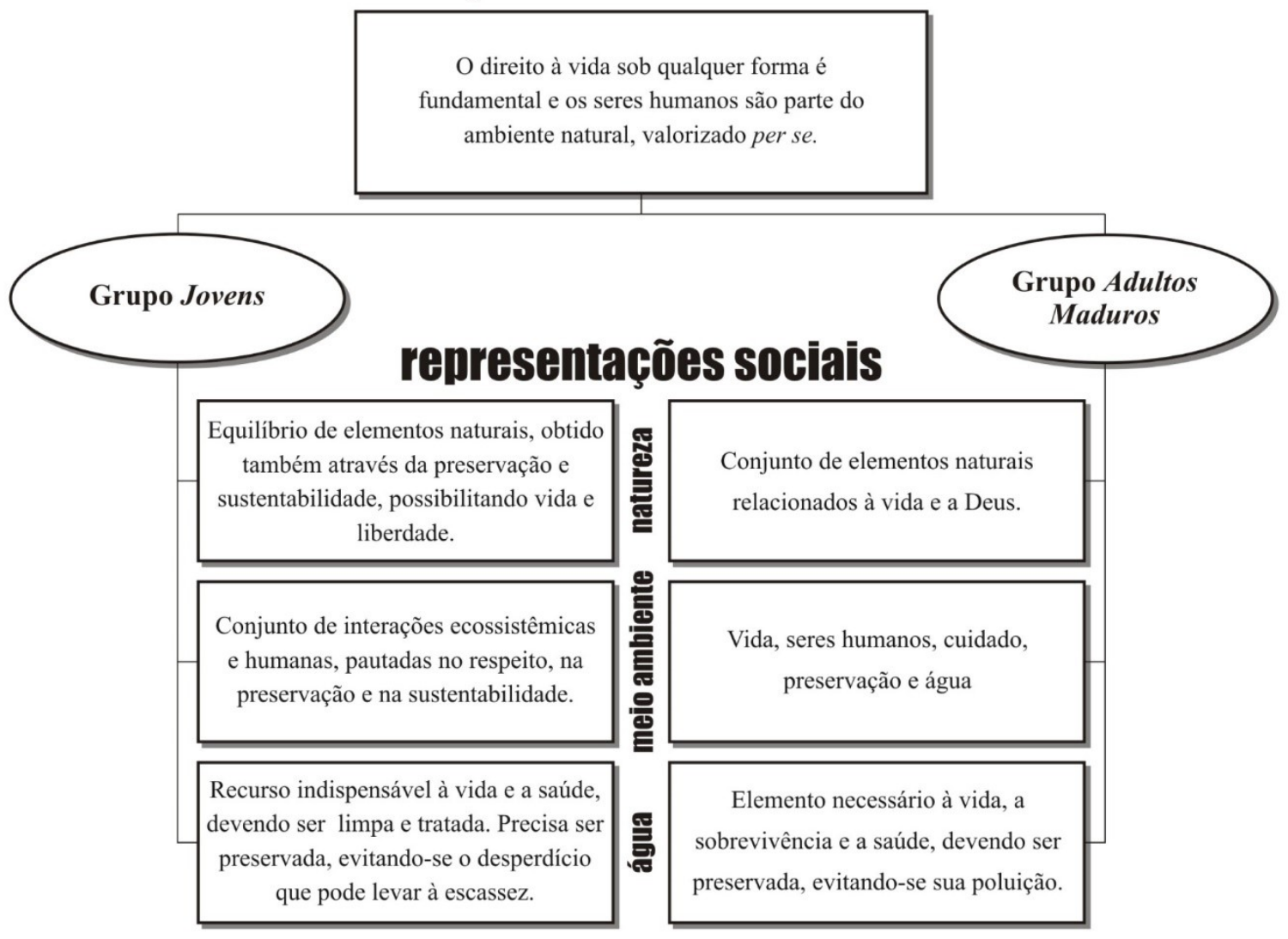

Figura 1. Representações sociais e crenças ambientais: comparação entre jovens e adultos maduros.

Conclui-se assim que os resultados obtidos por meio da Escala NEP e do questionário de evocações livres sugerem que se está presenciando uma transição de paradigmas ambientais em direção ao biocentrismo. No entanto, percebe-se que tal mudança não é simples ou rápida, e sim um processo que envolve contradições e impasses. Ao confrontar as crenças ambientais e as 
representações sociais de natureza, meio ambiente e água, verificou-se que a identificação ao novo paradigma ambiental, como expressa pelos resultados da Escala NEP, não foi de igual modo confirmada pelo estudo das representações sociais, que apontou paradoxalmente elementos diversos, ora semelhantes aos preceitos do mesmo paradigma, ora mais distante desses. É, pois, necessário considerar que as representações sociais apresentam-se em modo dinâmico e podem oferecer certa resistência às mudanças. Visto que as crenças ambientais são compartilhadas socialmente, espera-se que possam promover novos reflexos nas representações sociais com o passar do tempo (KUHNEN et al., 2011).

\section{CONSIDERAÇÕES FINAIS}

Os resultados referentes às crenças ambientais e às representações sociais indicaram que, possivelmente, a mídia e os próprios problemas ambientais estão atingindo ambas as faixas etárias de modo similar. Assim, o jovem e o adulto maduro, apesar de seus papéis distintos na sociedade e de terem vivenciado e estarem vivenciando momentos distintos no ciclo vital, apresentaram o mesmo sistema de crenças ambientais (biocêntrico) e elementos de representações sociais sobre a temática ambiental muito semelhantes entre si.

Ao considerar as questões ambientais como objetos sociais, entende-se que elas implicam diretamente sobre o cotidiano das pessoas, pois agem diretamente sobre a saúde, economia, qualidade de vida, entre outras instâncias. Por esse motivo, elas vêm ganhando espaço cada vez maior entre temas a serem discutidos em níveis midiáticos, políticos, sociais e acadêmicos. Nesse contexto, admite-se que o ser humano está modificando suas formas de se relacionar com o mundo. Parece estar havendo uma gradual passagem do paradigma antropocêntrico para o ecocêntrico, tendo sido possível verificar essa transição na população investigada. No entanto, tal passagem é permeada de contradições, uma vez que ainda evidenciam-se intenções de usufruto do meio ambiente apenas com vistas à satisfação de necessidades humanas e à própria preservação da espécie humana, como revelaram as representações sociais dos participantes, cuja investigação mostrou-se importante para o aprofundamento do tema das crenças ambientais.

Grupos sociais reinventam, rediscutem e redescobrem "teorias" a respeito dos mesmos temas de acordo com o momento histórico em que estão vivendo, que por sua vez influenciam representações e crenças. Dessa forma, novas ideias são integradas às mais antigas, formando-se novos pensamentos, ainda que envolvidos em contradição. Esses pensamentos poderão ser modificados novamente à medida que novas ideias forem assimiladas, o que reflete a complexidade inerente à construção das crenças e representações sociais de um grupo. 
Diretrizes para desenvolver hipóteses sobre o papel das crenças e das representações sociais no comportamento humano vêm sendo divulgadas pela comunidade científica. Mais especificamente, a área de estudos pessoa-ambiente vem tratando essa relação como bidirecional, ou seja, se aceita a premissa de que há uma mútua interferência entre a pessoa e o ambiente. Essa pesquisa contribui para o desenvolvimento da disciplina, visto ser orientada para problemas, com o objetivo de resolver complexas questões ambientais e a busca do bem-estar individual. Além disso, promove reflexões sobre a relação pessoa-ambiente que podem elucidar a formulação de políticas públicas mais consistentes em direção à preservação do ambiente, dentro de uma sociedade maior.

\section{REFERÊNCIAS}

ABRIC, J.-C. A abordagem estrutural das representações sociais. In MOREIRA, A. S. P.; OLIVEIRA, D. C. (Orgs.). Estudos interdisciplinares de representação social. Goiânia: AB., 1998, p. 27-38.

ABRIC, J.-C. Les représentations sociales: aspects théoriques. In: représentations. Paris: Press Universitaires de France, 1994. p. 11-35.

Pratiques sociales et

AMÉRIGO, M. Concepciones del ser humano y la naturaleza desde el antropocentrismo y el biosferismo. Medio Ambiente Y Comportamiento Humano, v.3, n.10, p.217-234, 2009. Disponível em: http://mach.webs.ull.es/PDFS/Vol10_3/Vol10_3_c.pdf. Acesso em: 23 abr. 2014.

BERTOLDO, R.; CASTRO, P.; BOUSFIELD, A. B. S. Pro-environmental beliefs and behaviors: two levels of response to environmental social norms. Revista Latinoamericana de Psicología, v.45, n.3, p.437-448, 2013. Disponível em: http://www.scielo.org.co/pdf/rlps/v45n3/v45n3a09.pdf. Acesso em: 23 abr. 2014.

CASTRO, P. Pensar a natureza e o ambiente: alguns contributos a partir da Teoria das Representações Sociais. Estudos de Psicologia, v.8, n.2, p.263-271, 2003. Disponível em: http://www.scielo.br/pdf/epsic/v8n2/19042.pdf. Acesso em: 23 abr. 2014.

CASTRO, P. Crenças e atitudes em relação ao meio ambiente e à natureza. In: SOCZA, L. (Org.). Contextos humanos e psicologia ambiental. 2. ed. Lisboa: Fundação Calouste Gulbekian, 2005. p.169-201.

CORRAL-VERDUGO, V. A structural model of proenvironmental competency. Environment and Behavior, v.34, n.4, p.531-549, 2002. Disponível em: http://eab.sagepub.com/content/34/4/531.short. Acesso em: 23 abr. 2014.

CORRAL-VERDUGO, V.; VARELA-ROMERO, C.; GONZÁLEZ-LOMELÍ, D. O papel da psicologia ambiental na promoção de competência pró-ambiental. In: TASSARA, E. T. O.; RABINOVICH, E. P.; GUEDES, M. D. C. (Orgs.). Psicologia e ambiente. São Paulo: EDUC, 2004. p.41-57.

CORRALIZA, J. A.; BETHELMY, L. C. Vinculación a la naturaleza y orientación por la sostenibilidad. Revista de Psicología Social, v.26, n.3, p.325-336, 2011. Disponível em: 
http://www.ingentaconnect.com/content/fias/rdps/2011/00000026/00000003/art00002. Acesso em: 23 abr. 2014.

CORRALIZA, J. A.; COLLADO, S.; BETHELMY, L. Spanish version of the new ecological paradigm scale for children. The Spanish Journal of Psychology, v.16, n.E27, 2013. Disponível em: http://journals.cambridge.org/action/displayAbstract?fromPage $=$ online\&aid $=8937112$. Acesso em: 23 abr. 2014.

DANCEY, C. P.; REIDY, J. Estatística sem matemática para psicologia: usando SPSS para Windows. 3. ed. Tradução L. Viali. Porto Alegre: Artmed, 2006.

DUNLAP, R. E. et al. Measuring endorsement of the new ecological paradigm: a revised NEP scale. Journal of Social Issues, v.56, n.3, p.425-442, 2000. Disponível em: http://academic.evergreen.edu/s/smitht/NEP\%20Revised\%20study\%202000.pdf. Acesso em: 23 abr. 2014.

GUIMELLI, C. Concerning the structure of social representations. Papers on social representations, v.2, n.2, p.85-92, 1993. Disponível em:

http://www.psych.lse.ac.uk/psr/PSR1993/2_1993Guime.pdf. Acesso em: 23 abr. 2014.

HAWCROFT, L. J.; MILFONT, T. L. The use (and abuse) of the new environmental paradigm scale over the last 30 years: a meta-analysis. Journal of Environmental Psychology, v.30, n.2, p.143-158, 2010. Disponível em: http://ac.els-cdn.com/S0272494409000772/1-s2.0S0272494409000772-main.pdf?_tid=1a8e6718-caff-11e3-956400000aab0f01\&acdnat=1398268456_fefa27bd95c2fe9e33de676a7d748585. Acesso em: 23 abr. 2014.

INGLEHART, R.; ABRAMSON, P. R. Measuring postmaterialism. American Political Science Review, v.93, n.3, p.665-677, 1999. Disponível em: http://www.jstor.org/stable/2585581. Acesso em: 23 abr. 2014.

JODELET, D. Representações sociais: um domínio em expansão. In: sociais. Rio de Janeiro: EdUERJ, 2001. p.17-44. . As representações

KUHNEN, A. Lagoa da Conceição: meio ambiente e modos de vida em transformação. Florianópolis: Cidade Futura, 2004.

KUHNEN, A. Comportamento sócio-espaciais e a relação humano-ambiental. In: KUHNEN, A.; CRUZ, R. M.; TAKASE, E. (Orgs.). Interações pessoa-ambiente e saúde. São Paulo: Casa do Psicólogo, 2009. p.15-35.

KUHNEN, A. Falando sobre os caminhos que chegaram à tese "Representações sociais de meio ambiente na Lagoa da Conceição/Florianópolis, SC". In: RIAL, C.; TOMIELLO, N.; RAFFAELLI, R. (Orgs.). A aventura interdisciplinar: quinze anos de PPGICH/UFSC. Blumenau: Nova Letra, 2010. p.231-233.

KUHNEN, A. et al. Relações entre representações sociais da água, da natureza e do meio ambiente e crenças ambientais. In: VILLODRES, M. C. H. et al. (Orgs.). Espaços urbanos y sostenibilidad: claves para la ciencia y la gestión ambiental. Almería: Universidad de Almería, 2011. p.331-340.

MOSCOVICI, S. On social representation. In: FORGAS, J.P. (Ed.). Social Cognition. London: European Association of Experimental Social Psychology/ Academic Press, 1981, p. 181-209. 
MOSCOVICI, S. A representação social da psicanálise. Rio de Janeiro: Zahar, 1978.

NASCIMENTO-SCHULZE, C. M. et al. Atitudes frente ao novo paradigma ambiental: um estudo no contexto turístico de Florianópolis. Revista de Ciências Humanas, n.6, p.215-224, 2002.

Disponível em: https://periodicos.ufsc.br/index.php/revistacfh/article/view/25849/22633. Acesso em: 23 abr. 2014.

OLIVOS, P.; ARAGONÉS, J. I. Test de asociaciones implícitas con la naturaleza: aplicación en España del "IAT-Nature". Revista de Psicología Social, v.28, n.2, p.237-245, 2013. Disponível em:

http://www.tandfonline.com/doi/abs/10.1174/021347413806196672?journalCode=rrps20\#preview. Acesso em: 23 abr. 2014.

PINHEIRO, J. Q. Comprometimento ambiental: perspectiva temporal e sustentabilidade. In: MARTÍNEZ, J. G.; DOMÉNECH, S. M. (Orgs.). Temas selectos de psicologia ambiental. México: UNAM-GRECO-FUNDACIÓN UNILIBRE, 2002. p.463-481.

PINHEIRO, J. Q. Psicologia ambiental brasileira no início do século XXI: sustentável? In: YAMAMOTO, O. H.; GOUVEIA, V. V. (Orgs.). Construindo a psicologia brasileira: desafios da ciência e prática psicológica. São Paulo: Casa do Psicólogo, 2003. p.279-313.

POLLI, G. M.; CAMARGO, B.V. Representações sociais do meio ambiente para pessoas de diferentes faixas etárias. Psicologia em Revista, v. 22, n. 2, p. 392-406. 2016. Disponível em: http://200.229.32.55/index.php/psicologiaemrevista/article/view/P.16789523.2016V22N2P392/107 52. Acesso em: 26 mar. 2019.

POLLI, G. M.; KUHNEN, A. Possibilidades de uso da teoria das representações sociais para os estudos pessoa-ambiente. Estudos de Psicologia, v.16, n.1, p.57-64, 2011. Disponível em: http://www.scielo.br/scielo.php?pid=S1413-294X2011000100008\&script=sci_arttext. Acesso em: 23 abr. 2014.

RAYMUNDO, L. D. S.; KUHNEN, A. A psicologia e a educação ambiental. Revista de Ciências Humanas, v.44, p.435-450, 2010. Disponível em:

https://periodicos.ufsc.br/index.php/revistacfh/article/view/2178-4582.2010v44n2p435/20918. Acesso em: 23 abr. 2014.

SEVILLANO, V.; ARAGONÉS, J. I. Percepción social de la conducta de los españoles en materia medioambiental. Revista Española de Investigaciones Sociológicas, v.126, p.127-149, 2009. Disponível em: http://www.reis.cis.es/REIS/PDF/REIS_126_051238571681079.pdf. Acesso em: 23 abr. 2014.

STOKOLS, D. Environmental Psychology. Annual Review of Psychology, v.29, p. 253-295, 1978. Disponível em: http://www.annualreviews.org/doi/pdf/10.1146/annurev.ps.29.020178.001345. Acesso em: 23 abr. 2014.

VALA, J. Representações sociais e psicologia social do conhecimento quotidiano. In: VALA, J.; MONTEIRO, M.B. (Orgs.). Lisboa: Calouste Gulbenkia, 2006, p. 457-502.

VALERA, S. Psicologia ambiental: bases teóricas y epistemológicas. In: IÑIGUEZ, L.; POL, E. (Orgs.). Cognición, representación y apropiación del espacio. Barcelona: Universidad de Barcelona Publicacions, 1996. p.1-14. 
WACHELKE, J. F. R.; CAMARGO, B. V. Representações sociais, representações individuais e comportamento. Revista Interamericana de Psicologia, 41, n. 3, 2007, p. 379-390. Disponível em: http://pepsic.bvsalud.org/scielo.php?pid=S0034-96902007000300013\&script=sci_abstract. Acesso em: 26 mar. 2019.

WIESENFELD, E. A Psicologia Ambiental e as diversas realidades humanas. Psicologia USP, v.16, n.1/2, p.53-69, 2005. Disponível em: http://www.scielo.br/scielo.php?pid=S010365642005000100008\&script=sci_arttext. Acesso em: 23 abr. 2014. 